\title{
Stress Corrosion Cracking of Steel and Aluminum in Sodium Hydroxide: Field Failure and Laboratory Test
}

\author{
Y. Prawoto, ${ }^{1}$ K. Sumeru, ${ }^{1,2}$ and W. B. Wan Nik ${ }^{3}$ \\ ${ }^{1}$ Faculty of Mechanical Engineering, Universiti Teknologi Malaysia, Skudai, 81310 Johor, Malaysia \\ ${ }^{2}$ Department of Refrigeration and Air Conditioning, Politeknik Negeri Bandung, Bandung 40012, Indonesia \\ ${ }^{3}$ Faculty of Maritime Studies and Marine Science, University Malaysia Terengganu, 21030 Kuala Terengganu, Malaysia
}

Correspondence should be addressed to Y. Prawoto, yunan.prawoto@gmail.com

Received 30 December 2011; Accepted 30 January 2012

Academic Editor: Pavel Lejcek

Copyright (C) 2012 Y. Prawoto et al. This is an open access article distributed under the Creative Commons Attribution License, which permits unrestricted use, distribution, and reproduction in any medium, provided the original work is properly cited.

\begin{abstract}
Through an investigation of the field failure analysis and laboratory experiment, a study on (stress corrosion cracking) SCC behavior of steel and aluminum was performed. All samples were extracted from known operating conditions from the field failures. Similar but accelerated laboratory test was subsequently conducted in such a way as to mimic the field failures. The crack depth and behavior of the SCC were then analyzed after the laboratory test and the mechanism of stress corrosion cracking was studied. The results show that for the same given stress relative to ultimate tensile strength, the susceptibility to SCC is greatly influenced by heat treatment. Furthermore, it was also concluded that when expressed relative to the (ultimate tensile strength) UTS, aluminum has similar level of SCC susceptibility to that of steel, although with respect to the same absolute value of applied stress, aluminum is more susceptible to SCC in sodium hydroxide environment than steel.
\end{abstract}

\section{Introduction}

Engineers in the field often assume that within the same group of materials, for example, group of ferrous or group of nonferrous, only the chemical composition is relevant when selecting materials for corrosive environments. Not so many of them consider the effect of heat treatment, let alone the microstructure. On the other hand, it is widely known that petroleum and natural gas systems can be contaminated with solutions that are sometimes very aggressive to engineering materials, such as steels and aluminums, which are used in the transport and processing of petroleum products. It has been reported from decades ago that up to a quarter of equipment failures in the petroleum refining industry are in some way associated with (stress corrosion cracking) SCC and hydrogen damage [1]. Although SCC of austenitic steel is the most common, steel with other microstructures can also undergo SCC. Therefore, SCC is not only unique to austenitic steel but also problematical in ferrite-pearlite and martensitic steels and aluminum alloys as well. This also has been known for long time [2]. Publications on the studies of SCC on ferrite-pearlite in the environment of $\mathrm{NaOH}$ were started quite a while ago, and it remains actively studied up to now $[3,4]$. The SCC behavior is highly dependant on the microstructure. El Sayed et al. studied SCC at various stress levels ranging from $10 \%$ to $100 \%$ of the (ultimate tensile strength) UTS of the materials [5]. However, they focused on the depth of the crack and did not analyze a morphology of the crack.

Similarly, SCC failure is also reported in aluminum and its derivative alloys [6-8]. It is also commonly understood that aluminum alloys that contain considerable amounts of soluble alloying elements, especially copper, magnesium, silicon, and zinc, are susceptible to SCC. They can fail by cracking along grain boundaries when simultaneously exposed to specific environments and sufficient magnitude of stresses. Well-known environments that can trigger SCC include but are not limited to water vapor, aqueous solutions, acids (such as acetic acid), organic liquids, liquid metals, and salt solutions. Stresses sufficient for crack initiation and crack propagation can be far below the stresses required for gross yielding. Unlike for high-strength materials such as steels, papers discussing about SCC of aluminum are rather scarce [7-10]. While majority of papers focus on 


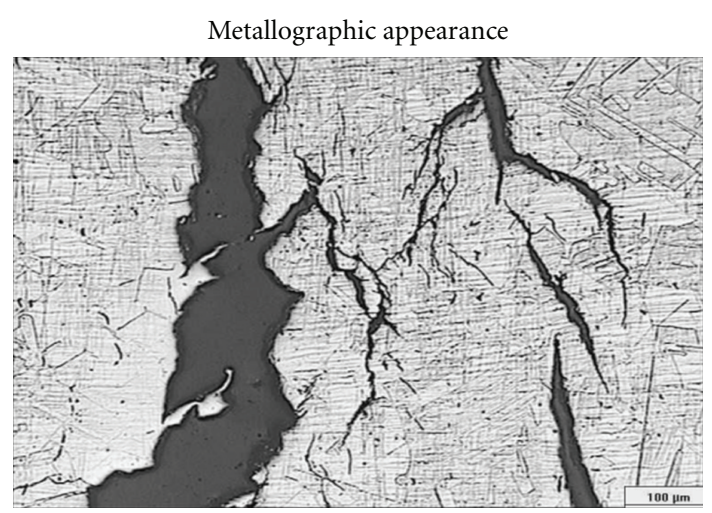

Failure in austenitic steel

(a)

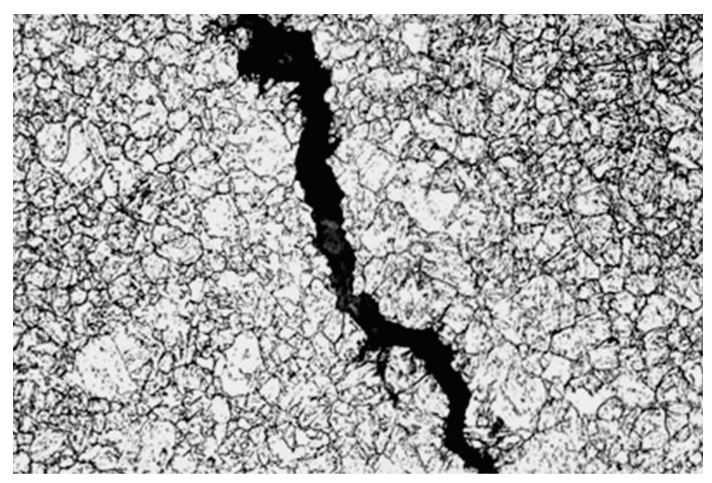

Failure in martensitic steel

(c)

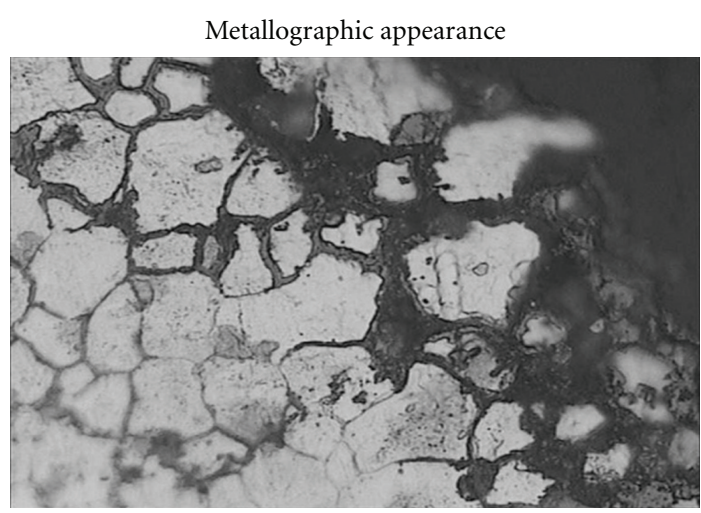

Failure in ferrite-pearlite steel

(b)

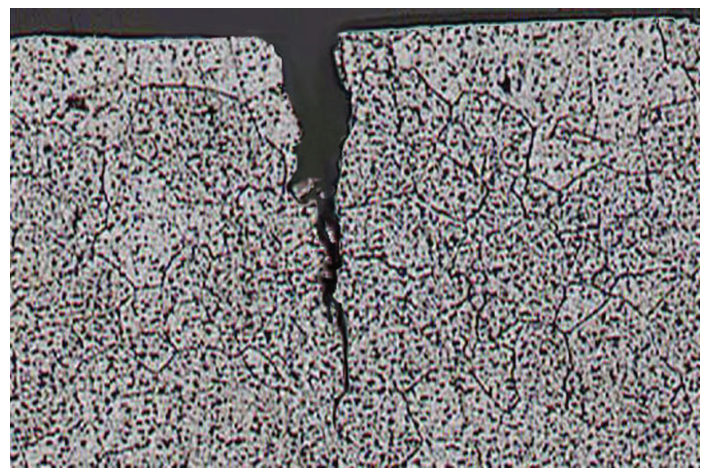

Failure in aluminum alloy

(d)

FIGURE 1: Appearance of the microstructures of samples extracted from field failure [12].

the chemical composition of aluminum alloys in various corrosive solutions, few of them focus on the effect of heat treatments or microstructures [11].

This paper is a combination of analysis of failed field specimens and laboratory experiments using three different microstructures: austenite, martensite, and ferrite-pearlite for steels and two different heat treatments for aluminum. The environment used was sodium hydroxide. The laboratory test was an accelerated version of what happens in the field.

\section{Case Study}

Figure 1 shows metallography of the samples from the field failures of both aluminum and the steel samples failed in similar environments. Although the environments in which all actual parts used were similar, the degree of the stress corrosion cracking is clearly different. For the steel, austenite was the most sensitive to SCC, followed by martensite, and finally ferrite-pearlite. All the samples were obtained from an oil company. While further detailed information is confidential, the environments in which they were being used contained some sodium hydroxide $(\mathrm{NaOH})$. All the pipes had been in service for more than 8 years. Further discussion only on the steel part of this project has been reported along with the basic general mechanism of the SCC [12], while the brief of the computational principle of this is available in the computational journal [13]. For the aluminum, the shape of the crack tip is somehow similar to that of fatigue crack tip, which is wedge-shaped crack morphology typically associated with thermal and/or mechanical fatigue cracking [14].

Because of the difference in concentrations used, stress levels applied, and temperatures involved, direct comparison of these cases cannot be made without laboratory accelerated experiment. Therefore, similar but an accelerated version of the simulation was created in the laboratory.

\section{Brief on Stress Corrosion Cracking}

SCC is fundamentally different from other types of corrosion. It needs a combination of mechanical-and-corrosive environment, and the failure due to SCC only occurs under specific conditions. It is highly chemically specific in that certain alloys are likely to undergo cracking only when exposed to a small number of chemical environments. Similar to the nature of the fatigue failure, in industries, SCC progress is very slow and difficult to detect until sudden failure. Typically, outside appearance of the SCC does not reflect the condition inside. This fact often deceives engineers 
TABLE 1: (a) Chemical composition analysis results of steel materials [12]. (b) Chemical composition analysis results of aluminum alloys.

(a)

\begin{tabular}{|c|c|c|c|c|c|c|}
\hline \multirow{2}{*}{$\%$ wt. } & \multicolumn{3}{|c|}{ Field failure case study } & \multicolumn{3}{|c|}{ Ferrite-pearlite tube } \\
\hline & Ferrite-pearlite tube & Martensite tube & Austenite tube & Ferrite-pearlite tube & Martensite tube & Austenite tube \\
\hline $\mathrm{C}$ & 0.274 & 0.494 & 0.164 & 0.3 & & 0.093 \\
\hline $\mathrm{Si}$ & 0.178 & 0.167 & 0.044 & 0.1 & & 0.437 \\
\hline $\mathrm{Mn}$ & 0.462 & 0.379 & 0.896 & 0.2 & & 0.672 \\
\hline $\mathrm{P}$ & 0.016 & 0.019 & 0.032 & 0.0 & & 0.041 \\
\hline S & 0.022 & 0.030 & 0.021 & 0.0 & & 0.028 \\
\hline $\mathrm{Cr}$ & Negligible & negligible & 12.128 & negli & & 13.427 \\
\hline $\mathrm{Fe}$ & Balance & Balance & Balance & Bala & & Balance \\
\hline
\end{tabular}

(b)

\begin{tabular}{lcr}
\hline$\%$ wt. & Field failure sample & Laboratory sample \\
\hline $\mathrm{Si}$ & 0.692 & 0.674 \\
$\mathrm{Fe}$ & 0.223 & 0.280 \\
$\mathrm{Cu}$ & 0.044 & 0.041 \\
$\mathrm{Cr}$ & 0.033 & 0.031 \\
$\mathrm{Ni}$ & 0.009 & 0.007 \\
$\mathrm{Al}$ & Balance & Balance \\
\hline
\end{tabular}

working on the fields. Stress corrosion cracking of carbon steels and aluminum is relatively common in many parts, especially in the oil and gas sectors as well as in chemical manufacture.

Although there is much published research into SCC problems, complete elimination of the SCC problem is difficult, especially in oil and gas industry or even in general engineering applications. Therefore, suitable approaches are needed not only to eliminate this problem and guarantee the safety of human life but also to avoid the consequences of the malfunction. Common SCC avoidance programs such as materials selection, corrosion inhibitors, protective coatings and cathodic protection are usually preferred method to overcome the corrosion predicament.

Numerous papers on materials with different microstructures are available individually but studies where different microstructures have been examined under similar conditions and compared directly are very rare, if it is available at all. Some used martensite tube and immersion in $\mathrm{NaOH}, \mathrm{K}_{2} \mathrm{CO}_{3}$, and their combination. The effect of variation of microstructure on SCC is also shown in other researches as well $[15,16]$, which reported on the susceptibility to SCC in $\mathrm{Na}_{2} \mathrm{~S}$ of steels for various samples with assorted heat treatments and clarified the influence of the heat treatment parameters on the susceptibility to SCC.

Mechanisms of Stress Corrosion Cracking. The mechanisms of SCC are relatively widely discussed and therefore will be omitted here $[17,18]$. Furthermore, both stages, Crack Initiation and Crack Propagation, produce a unique crack shape depending upon their mechanism. In short, the mechanisms for crack initiation include mechanical features, local galvanic cells initiating dissolution, pitting type crack initiation, and initiation at a stress-induced phenomenon. The crack growth mechanisms include film rupture mechanism, film cleavage mechanism, adsorption induced cleavage, adsorption induced plasticity, atomic surface mobility, and corrosion tunnel model.

\section{Experiment}

4.1. Field Failure Case. The samples extracted from field failure were total of four samples, three steel samples, and one aluminum sample. Figure 1 shows representatives of metallography of the field failure cases of four samples received. All of them came from comparable usage conditions. The comprehensive data are not disclosed here due to the agreement with the owner. All materials were retrieved from sites that had alkalinity of approximately $1.1 \%$ and $\mathrm{pH}$ of 9.2. The main source of this environment was $\mathrm{NaOH}$.

The chemical composition analysis results for steel and aluminum samples are shown in Tables 1(a) and 1(b), respectively. They are austenitic stainless steel, low carbon steel, and aluminum 6XXX series. Glow discharge spectroscopy was used to obtain the data. For the accelerated simulation, similar materials available in the market were used.

4.2. Laboratory Experiment. Following the ASTM standard [19], both the steel and aluminum samples were shaped into C-ring samples.

Specimen Preparation. The low carbon steel and austenitic stainless steel pipes were used in standard size with NPS 


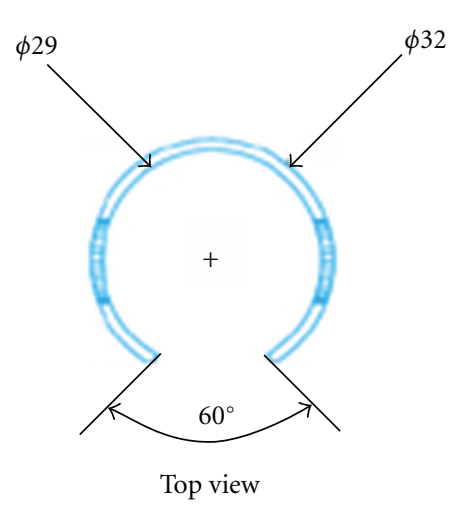

(a)

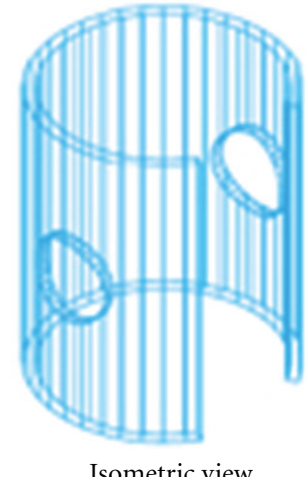

(b)

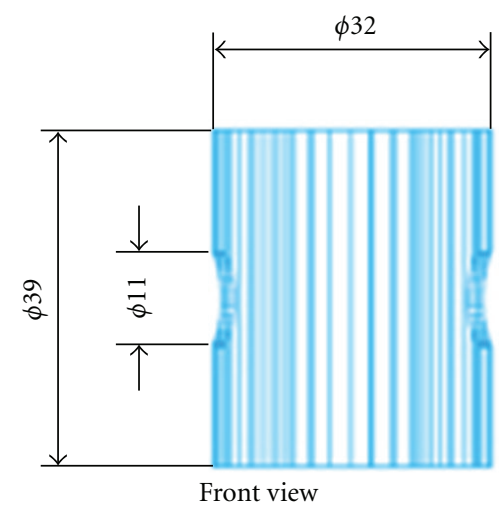

(c)

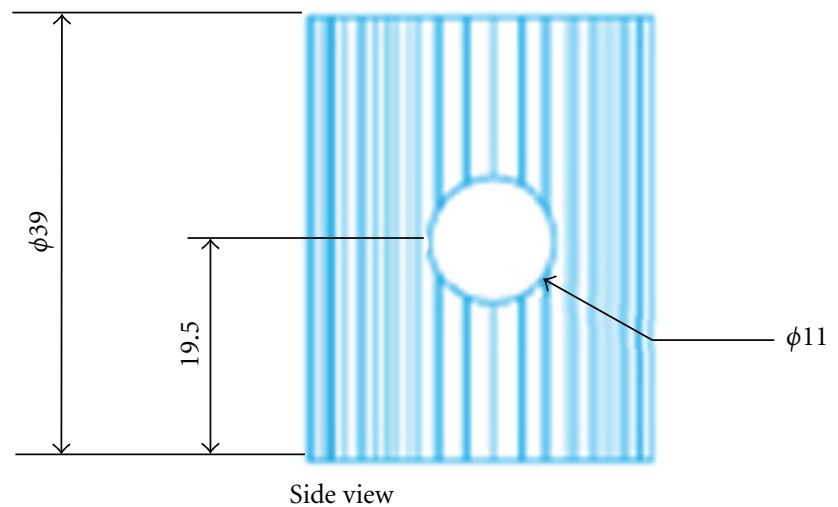

(d)

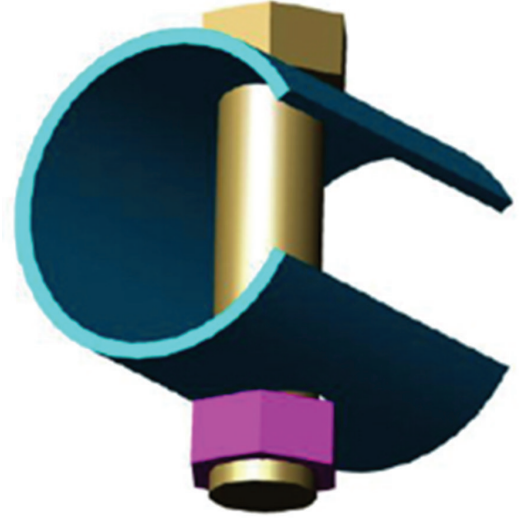

(e)

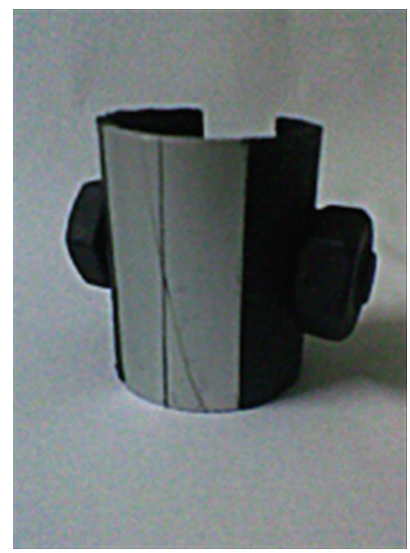

(f)

FIGURE 2: Appearance of C-ring specimen. Away from the areas of interest, coating was applied to avoid corrosion. 
designator number 1.5. Its outer diameter is $48.3 \mathrm{~mm}$ (1.9 in.) with thickness $3.68 \mathrm{~mm}$ (0.145 in.). Figure 2 shows the appearance of the C-ring specimen that was used. This specimen was machined with a Computerized Numerical Control (CNC) machine to the designed dimensions.

The low carbon steel specimens were then undergone heat treating to obtain ferrite/pearlite (FP) and martensite $(\mathrm{M})$, while the stainless steel was austenite (A). For the aluminum 6XXX series sample, two different heat treatments, namely, HT1 (precipitation heat treatment) and HT2 (annealing), was performed. Bolt and nuts was utilized to apply particular stress levels according to the ASTM standard. Three different stress values were applied, $40 \%$, $75 \%$, and $95 \%$, of the material's UTS. The UTS values of the samples were obtained from tensile tests. This is the best choice of stress value because changes of behavior in SCC can be evaluated easily. The following equation was used to calculate the stress that has been applied to a C-ring specimen:

$$
\mathrm{OD}_{f}=\mathrm{OD}-\Delta, \quad \Delta=f \pi \frac{D 2}{4 E t Z},
$$

where OD is the outside diameter of C-ring before stressing, in. (or $\mathrm{mm}$ ), $\mathrm{OD}_{f}$ is the outside diameter of stressed C-ring, in. (or $\mathrm{mm}$ ), $f$ is the desired stress, $\mathrm{MPa}$ (or psi) (within the proportional limit), $\Delta$ is the change of OD giving desired stress, $\mathrm{mm}$ (or in.), $D$ is the mean diameter $(\mathrm{OD}-t), \mathrm{mm}$ (or in.), $t$ is the wall thickness, $\mathrm{mm}$ (or in.), $E$ is the modulus of elasticity, $\mathrm{MPa}$ (or psi), and $Z$ is the a correction factor for curved beams.

After the specimens were fully prepared, they underwent immersion testing in sodium hydroxide $(\mathrm{NaOH}) 50 \%$ at $80^{\circ} \mathrm{C}$ for several different periods of time. It is worth noticing here that to reduce the effect of other corrosion modes, coating was applied to the samples except in the areas of interest.

\section{Results and Discussion}

The UTS values for the samples used were $421.3 \mathrm{MPa}$ for ferrite pearlite sample, 949.4 MPa for martensite sample, 684.6 MPa for austenite sample, and $119 \mathrm{MPa}$ for aluminum alloy 6XXX series sample, respectively. The representative results for the SCC test are shown in Figure 3. It is worth noting here that our intermediate observation revealed an indication of grain boundary thickening on the austenite sample and aluminum sample prior to crack formation. This could be a sign of hydrogen reacting with the material or a result of oxidation. This oxidation is preferable to occur at the grain boundary. Similar observations were also reported [20]. Chemically, the thickening indicates that there is segregation, concentrated near the grain, while physically it implies increasing of the dislocation density. At $95 \%$ of the UTS the ferrite pearlite sample started to develop small amount (1-2 grains) of SCC, while the martensite sample had more than $100 \mu \mathrm{m}$ deep SCC and the austenite sample has almost twice that depth of SCC. For aluminum samples, both HT1 (precipitation hardened) and HT2 (annealed), they clearly show cracking taken place at the grain boundary. Reports of similar observation are also available although scarcely [21]. Further investigation also revealed that HT1 sample also shows some indication of general surface corrosion attack.

On all samples, the tendency of the crack to be intergranular was very obvious. Its appearance is similar to that of hydrogen damage, where the hydrogen atoms penetrate into the grain boundary.

The initiation type for the ferrite pearlite can be classified as local galvanic cells initiating dissolution, where pearlite has corroded more. Similarly, the martensite sample also has this tendency, with the carbide being corroded first. Austenite and aluminum samples, both the HT1 and HT2, on the other hand, show signs of pitting type crack initiation, where the grain boundary and the twin are the most extensively pitted.

Once the initiation was successful, the corrosion then moved to the second stage, propagation. The propagation type of cracks in ferrite pearlite occurred by film rupture mechanism, whereas corrosion tunnel model was visible in the austenite sample. The film rupture mechanism was supported by evidence of corrosion at the surface of the ferrite-pearlite in the form of general corrosion attack. On the other hand, the symptoms of general attack corrosion were not observed in the austenite nor aluminum HT2 sample. The austenite and the HT2 samples show clear evidence of corrosion tunnels, where the twin microstructure and the grain boundary in the figure are some of the entry points and subsequently become preferred locations for tunnel growth. This observation is solely based upon the morphology evaluation. The crack tip of HT1 sample similar to that of martensite sample. Although this does not necessarily mean that the mechanism is the same, this finding is important for computational bases, as the continuum mechanics and fracture mechanics differentiate the crack tip shapes.

The crack depth as a function of the applied stress is shown in Figure 4. Generally, aluminum shows significantly more susceptible to SCC than steel is. With respect to the absolute values of the applied stress, the rank of the crack depth is austenite, ferrite-pearlite, and martensite, for the steel and HT1 followed by HT2 for aluminum. However, when this applied stress is transferred to the percentage of the UTS, the ranking changes to austenite, martensite, and ferrite-pearlite (Figure 5) for the steel, and HT1 followed by HT2 for aluminum samples.

Another important finding is that when they are expressed in term of relative applied stress (to UTS), steel and aluminum have similar susceptibility. The laboratory results match the observation of the field failures. The morphology of the cracks on all different laboratory samples is very similar to that of samples from the field failures. The tendency to crack branching is clearly much stronger on a sample with austenite microstructure than on a sample with ferrite-pearlite. Similarly, for aluminum samples, the crack branching is visible on both the HT1 and HT2 samples. This information is very useful, especially to initiate continuum mechanics-based computational modeling for fracture mechanics $[22,23]$. 


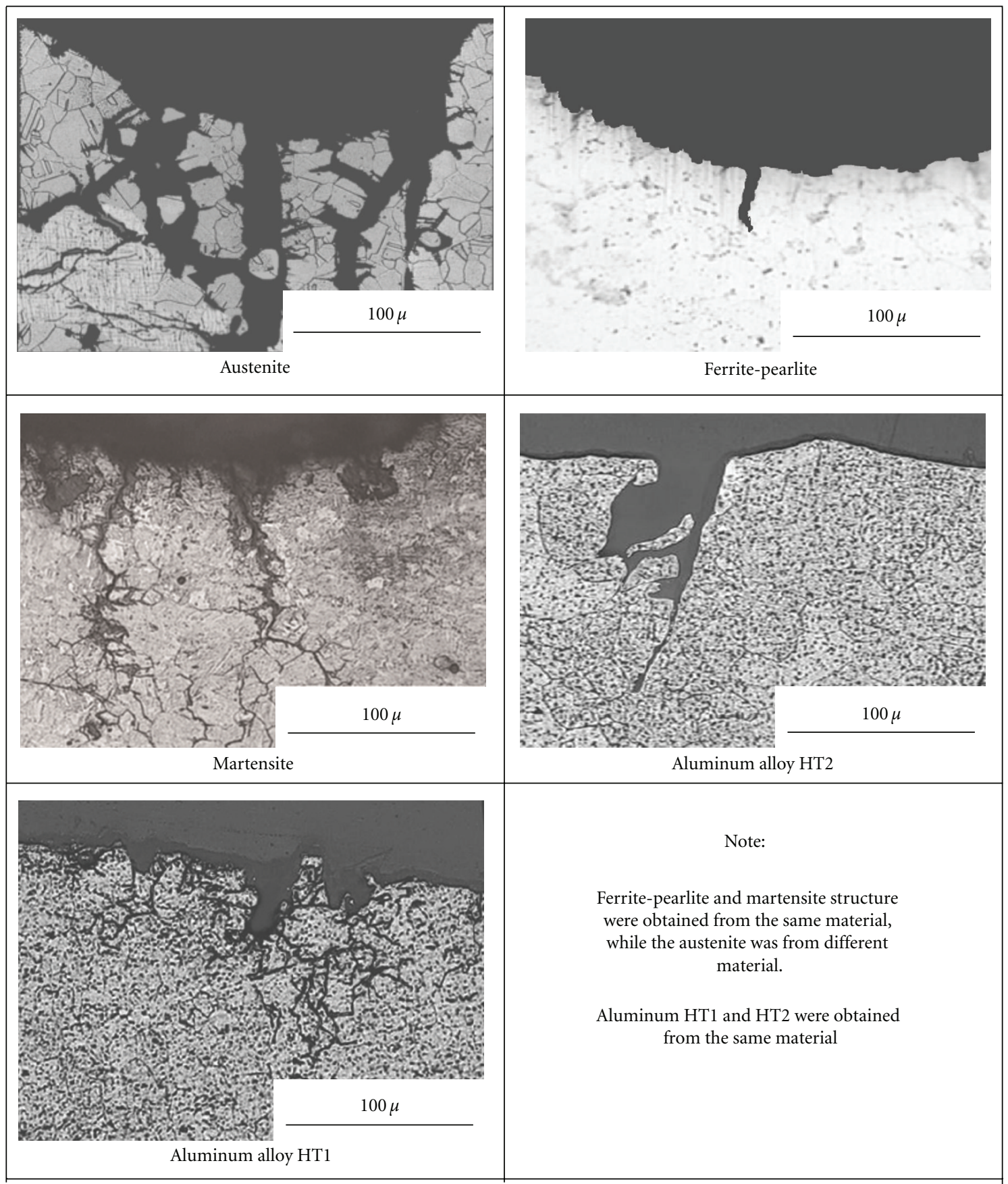

FIgURE 3: Appearance of the crack shapes for steels and aluminums.

\section{Conclusion}

Characterization of the SCC of steel and aluminum martensite in $\mathrm{NaOH}$ was performed. For steel samples, three different microstructures: austenite, ferrite-pearlite, while for the aluminum samples microstructural variation was obtained by HT1 and HT2. Expressed in absolute applied stress, aluminum has substantially higher susceptibility than steel. However, they become very similar when they are expressed in term of percentage of their UTS. For an applied load of constant percentage of ultimate tensile strength, among steel microstructures, austenite was found to be the most prone to SCC while for aluminum, HT1 is proven to be more susceptible to SCC than HT2 sample. Although there are limitations to this observation, such as neglecting the effect of the chemical composition of the material, the observation is useful for both computational purposes as well as for practicing engineers in the field. The result shows that each microstructure produces a unique crack shape that can be used as a basis for computational model construction. 

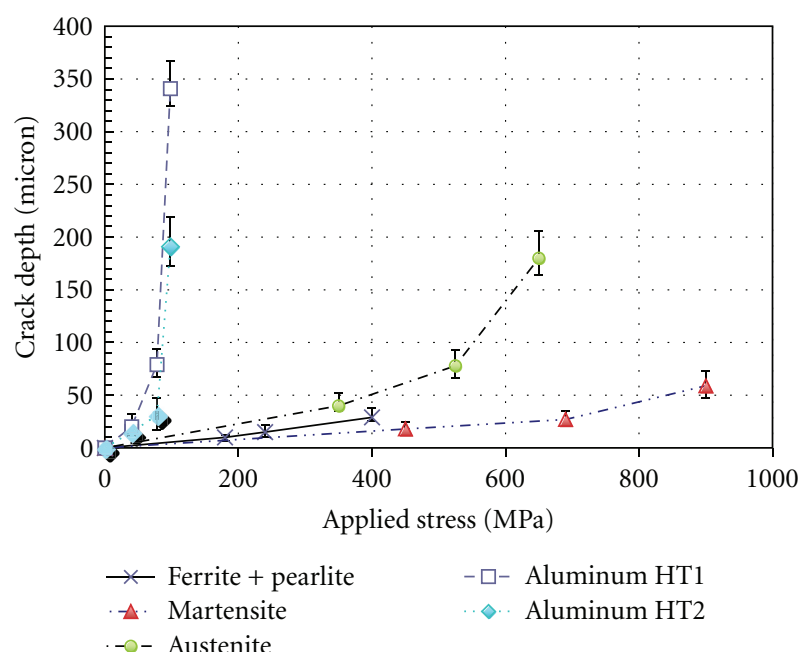

Figure 4: Crack depth as a function of applied stress.

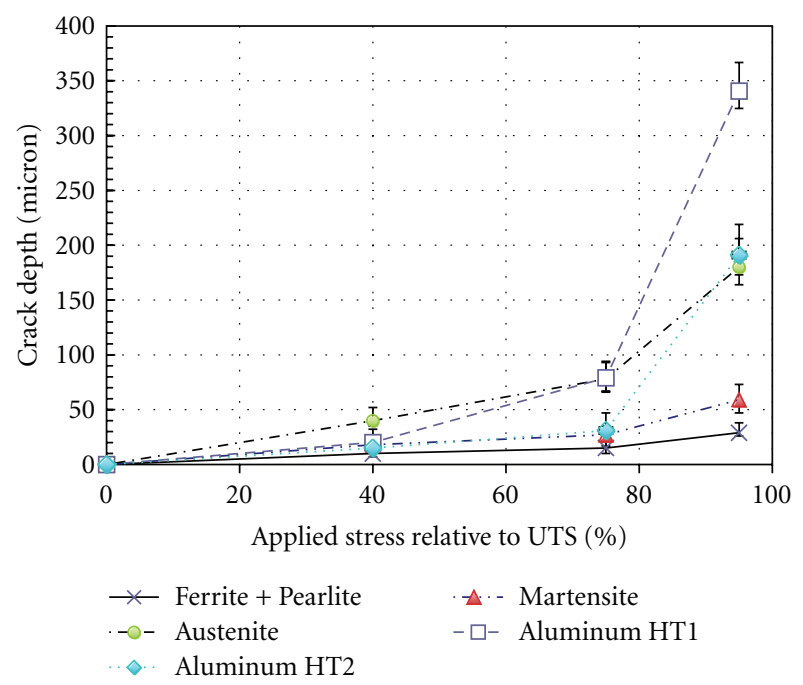

Figure 5: Crack depth as a function of applied stress.

Similarly, the results are also useful for practical engineers working in the field. The mechanism of SCC of the austenite and aluminum was found to be dominated by the corrosion tunnel model, while SCC of the other microstructures occurred by film rupture.

\section{References}

[1] T. P. Hoar and J. M. West, "Mechano-chemical anodic dissolution of austenitic stainless steel in hot chloride solution," Proceeding of the Royal Society A, vol. 268, pp. 304-315, 1962.

[2] T. P. Hoar and J. C. Scully, "Mechanochemical anodic dissolution of austenitic stainless steel in hot chloride solution at controlled electrode potential," Journal of Electrochemical Society, vol. 111, no. 3, pp. 348-352, 1964.

[3] J. L. Albarran, L. Martinez, and H. F. Lopez, "Effect of heat treatment on the stress corrosion resistance of a microalloyed pipeline steel," Corrosion Science, vol. 41, no. 6, pp. 1037-1049, 1999.
[4] N. Nakayama, "Inhibitory effects of nitrilotris(methylenephosphonic acid) on cathodic reactions of steels in saturated $\mathrm{Ca}(\mathrm{OH})_{2}$ solutions," Corrosion Science, vol. 42, no. 11, pp. 1897-1920, 2000.

[5] A. El-Sayed, K. M. El-Sobki, and V. K. Gouda, "Stress corrosion behaviour of 410 stainless steel in boiling 70\% $\mathrm{NaOH}$ solution," Surface Technology, vol. 14, no. 3, pp. 245256, 1981.

[6] A. K. Jha, P. R. Narayanan, K. Sreekumar, and P. P. Sinha, "Cracking of $\mathrm{Al}-4.5 \mathrm{Zn}-1.5 \mathrm{Mg}$ aluminium alloy propellant tank-a metallurgical investigation," Engineering Failure Analysis, vol. 17, no. 2, pp. 562-570, 2010.

[7] A. Conde, B. J. Fernández, and J. J. de Damborenea, "Characterization of the SCC behaviour of $8090 \mathrm{Al}-\mathrm{Li}$ alloy by means of the slow-strain-rate technique," Corrosion Science, vol. 40, no. 1, pp. 91-102, 1998.

[8] A. F. Oliveira Jr., M. C. de Barros, K. R. Cardoso, and D. N. Travessa, "The effect of RRA on the strength and SCC resistance on AA7050 and AA7150 aluminium alloys," Materials Science and Engineering A, vol. 379, no. 1-2, pp. 321-326, 2004.

[9] R. P. Wei, M. Gao, and P. S. Pao, "The role of magnesium in CF and SCC of 7000 series aluminum alloys," Scripta Metallurgica, vol. 18, no. 11, pp. 1195-1198, 1984.

[10] Y. E. Wu and Y. T. Wang, "Enhanced SCC resistance of AA7005 welds with appropriate filler metal and post-welding heat treatment," Theoretical and Applied Fracture Mechanics, vol. 54, no. 1, pp. 19-26, 2010.

[11] J. C. Lin, H. L. Liao, W. D. Jehng, C. H. Chang, and S. L. Lee, "Effect of heat treatments on the tensile strength and SCCresistance of AA7050 in an alkaline saline solution," Corrosion Science, vol. 48, no. 10, pp. 3139-3156, 2006.

[12] Y. Prawoto, A. Moin, M. Tadjuddin, and W. B. Wan Nik, "Effect of microstructures on SCC of steel: field failure analysis case study and laboratory test result," Engineering Failure Analysis, vol. 18, no. 7, pp. 1858-1866, 2011.

[13] Y. Prawoto, "Incorporating the morphological difference of corrosion cracks in computational fracture mechanics approach," Computational Materials Science, vol. 56, pp. 166168, 2012.

[14] D. L. McDowell and F. P.E. Dunne, "Microstructure-sensitive computational modeling of fatigue crack formation," International Journal of Fatigue, vol. 32, no. 9, pp. 1521-1542, 2010.

[15] G. Rondelli, B. Vicentini, and E. Sivieri, "Stress corrosion cracking of stainless steels in high temperature caustic solutions," Corrosion Science, vol. 39, no. 6, pp. 1037-1049, 1997.

[16] A. S. Afolabi and J. O. Borode, "Stress corrosion cracking susceptibility of medium carbon steel in caustic and potash media," Australian Journal of Technology, vol. 10, pp. 165-170, 2007.

[17] R. O. Rihan and S. Nešić, "Erosion-corrosion of mild steel in hot caustic. Part I: NaOH solution," Corrosion Science, vol. 48, no. 9, pp. 2633-2659, 2006.

[18] J. Y. Zou and D. T. Chin, "Mechanism of steel corrosion in concentrated $\mathrm{NaOH}$ solutions," Electrochimica Acta, vol. 32, no. 12, pp. 1751-1756, 1987.

[19] ASTM Standard: G38-07, Standard Practice for Making and Using C-Ring Stress-Corrosion Test Specimen, ASTM Annual Book of Standards, 2007.

[20] F. Goutier, S. Valette, A. Vardelle, and P. Lefort, "Oxidation of stainless steel $304 \mathrm{~L}$ in carbon dioxide," Corrosion Science, vol. 52, no. 7, pp. 2403-2412, 2010. 
[21] G. Svenningsen, M. H. Larsen, J. H. Nordlien, and K. Nisancioglu, "Effect of high temperature heat treatment on intergranular corrosion of $\mathrm{AlMgSi}(\mathrm{Cu})$ model alloy," Corrosion Science, vol. 48, no. 1, pp. 258-272, 2006.

[22] K. S. Chan, "Roles of microstructure in fatigue crack initiation," International Journal of Fatigue, vol. 32, no. 9, pp. 1428$1447,2010$.

[23] M. R. Wenman, K. R. Trethewey, S. E. Jarman, and P. R. ChardTuckey, "A finite-element computational model of chlorideinduced transgranular stress-corrosion cracking of austenitic stainless steel," Acta Materialia, vol. 56, no. 16, pp. 4125-4136, 2008. 

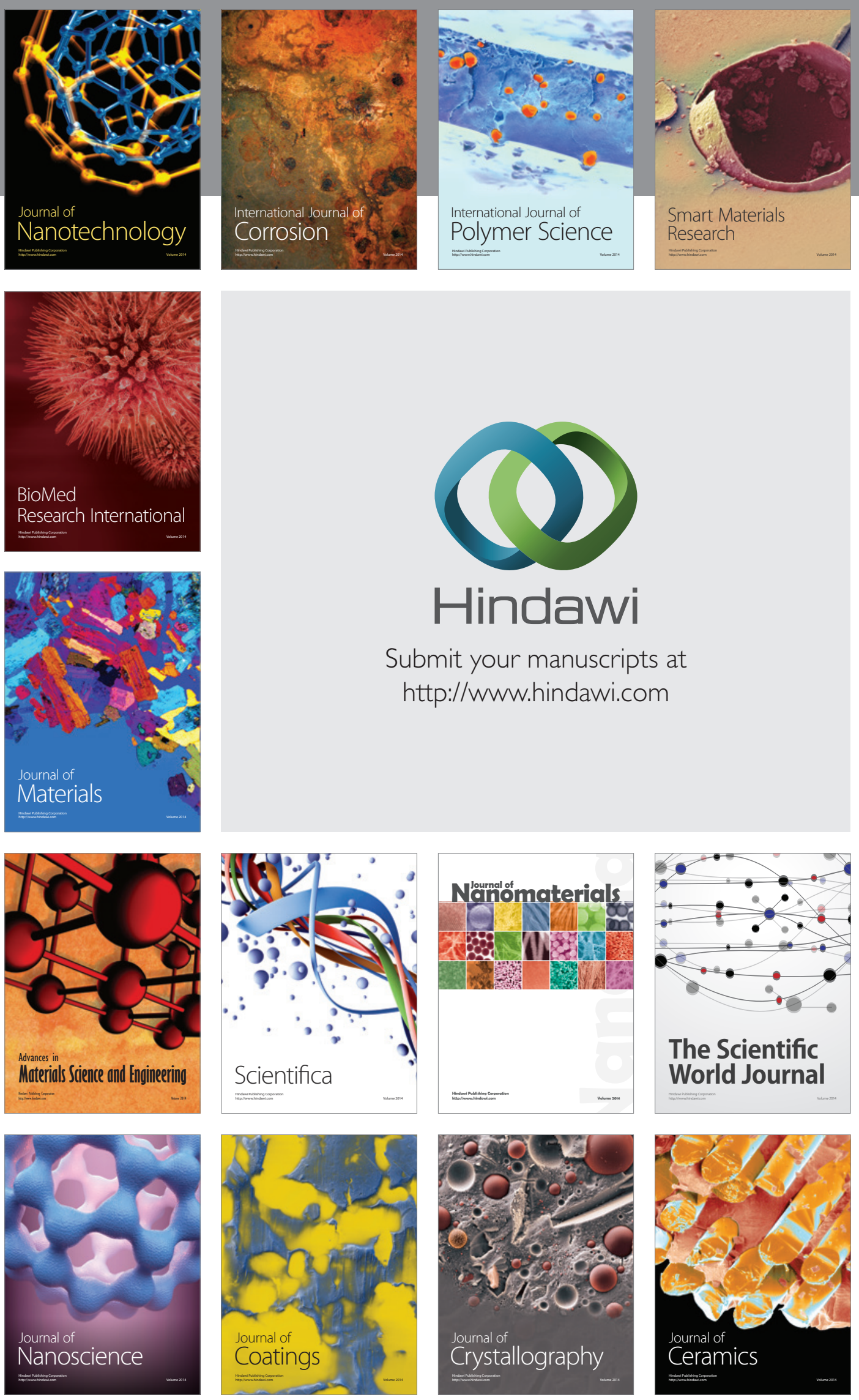

The Scientific World Journal

Submit your manuscripts at

http://www.hindawi.com

\section{World Journal}

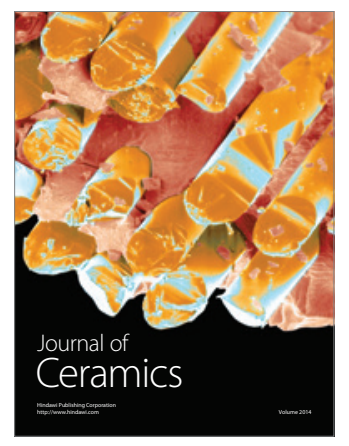

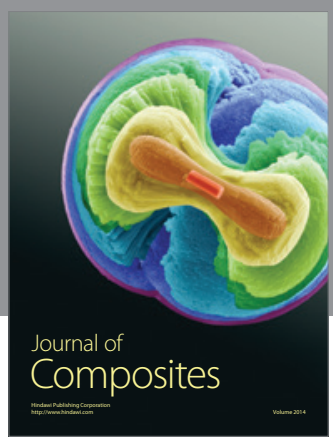
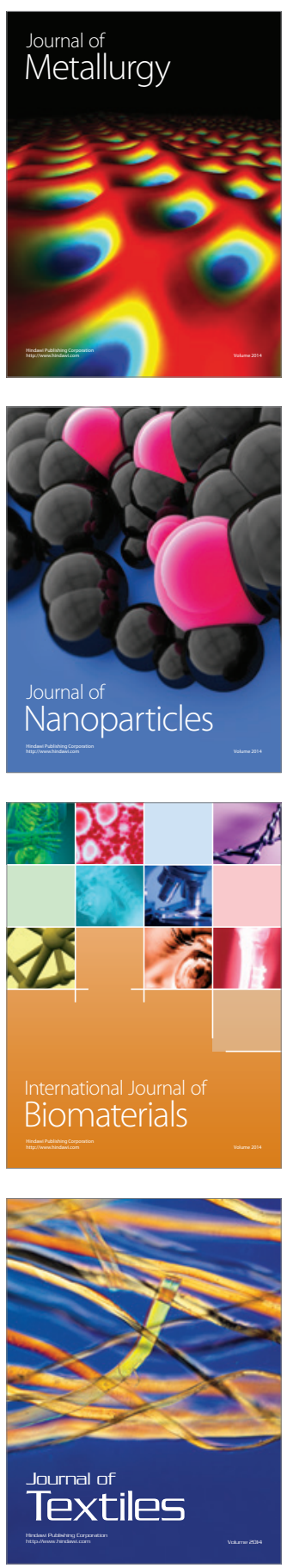